\title{
Adsorptive removal of various phenols from water by South African coal fly ash
}

\author{
JH Potgieter ${ }^{1}$, SO Bada ${ }^{2}$ and SS Potgieter-Vermaak ${ }^{1,3 *}$ \\ ${ }^{1}$ Chemistry and Materials Division, School of Biology, Chemistry and Health Sciences, Manchester Metropolitan University, \\ All Saints Campus, Oxford Street, Manchester, M15 6GD, UK \\ ${ }^{2}$ School of Chemical and Metallurgical Engineering, University of the Witwatersrand, Private Bag X3, Wits, 2050, South Africa \\ ${ }^{3}$ Molecular Science Institute, School of Chemistry, University of the Witwatersrand, Private Bag X3, Wits, 2050, South Africa
}

\begin{abstract}
South African coal fly ash (SACFA) was used to effectively remove phenol, 2-nitrophenol and 4-nitrophenol from wastewater. The rate of adsorption follows first-order kinetics before attaining equilibrium with the sorption rate $\left(K_{a d}\right)$ obtained being the highest for 4-nitrophenol ( $p$-nitrophenol) $\left(7.0 \times 10^{-3} / \mathrm{h}\right)$, followed by phenol $\left(1.2 \times 10^{-3} / \mathrm{h}\right)$ and 2-nitrophenol (o-nitrophenol) $\left(1.0 \times 10^{-3} / \mathrm{h}\right)$. Batch studies were performed to evaluate the adsorption process, and it was found that the Freundlich isotherm effectively fits the experimental data for the adsorbates better than the Langmuir model, with the fly ash having the highest adsorption capacity of $6.51 \times 10^{-2} \mathrm{mg} / \mathrm{g}$ for 4-nitrophenol, $6.00 \times 10^{-2} \mathrm{mg} / \mathrm{g}$ for 2-nitrophenol and $6.31 \mathrm{x} 10^{-2} \mathrm{mg} / \mathrm{g}$ for phenol. The fly ash was found to adsorb $90.2 \%$ of phenol, $88.9 \%$ of 2-nitrophenol and $92.6 \%$ of 4-nitrophenol at an initial concentration of $20 \mathrm{mg} / \ell$. The desorption studies suggested that the desorption of 4-nitrophenol was the most difficult of the three adsorbates to be desorbed. The desorption efficiency was $17.9 \%$ for phenol, $18.8 \%$ for 2 -nitrophenol and $10.2 \%$ for 4-nitrophenol. This work proved that SACFA can be used as an efficient adsorbent material for removal of phenol from water and wastewater.
\end{abstract}

Keywords: fly ash, phenol, nitrophenols, adsorption-desorption, batch study

\section{Introduction}

Wastewaters containing phenolic compounds are a serious environmental problem, and these waters cannot simply be released into the environment without treatment. The toxic and hazardous nature of phenols and their derivatives have been well documented (Greminger et al., 1982; Brandt et al., 1997; Bülbül et al., 1997; Denizli et al., 2004) and can cause several health problems (Slein and Sansone, 1980). Phenolic compounds have been classified as high-priority pollutants by the USA EPA (Environmental Protection Agency, 1984). Phenolic compounds are usually present in wastewater generated from the paint, solvent, petrochemical, coal conversion, pharmaceutical, plastic, iron-steel and paper and pulp industries.

Several methods are currently used for the removal of phenol and its derivatives from wastewater, e.g. microbial degradation, chemical oxidation, incineration, solvent extraction and irradiation (Munaf et al., 1997; Bertoncini et al., 2003; Khalid et al., 2004; Aksu, 2005; Denizli et al., 2005). However, by far the most frequently used technology is adsorption by a solid phase. Several different adsorbent solids such as activated carbon (Garcia-Araya et al., 2003; Nouri et al., 2002), silica (Hanna et al., 2002), glass powder (Atun, 1992), polymeric resins (Wagner and Schultz, 2001; Abburi, 2003), fly ash (Akgerman and Zardkoohi, 1996; Kao et al., 2000; Sarkar et al., 2005; Sarkar and Acharya, 2006; Srivastava et al., 2006; Viraraghavan and Alfaro, 1998), peat (Allen, 1987; Viraraghavan and Alfaro, 1998), kaolinite

\footnotetext{
* To whom all correspondence should be addressed.

푱 +32 3820 2346; fax: +32 3820 2378;

e-mail: sanja.potgieter@ua.ac.be

Received 15 October 2008; accepted in revised form 25 November 2008.
}

(Barhoumi et al., 2003) and zeolites (Koh and Dixon, 2001; Sismanoglu and Pura, 2001) have all been proposed to remove phenolic pollutants from wastewater. Activated carbon is, however, an expensive material, so many of the other alternatives suggested become very attractive from a cost point of view. In this regard fly ash is a very attractive option, because it is cheap, widely available and has good mechanical stability for handling purposes and employment in adsorption columns.

The use of fly ash as a means to remove both inorganic heavy metals (Bayat, 2002; Gangoli et al., 1975) and organic phenolic compounds (Akgerman and Zardkoohi, 1996; Kao et al., 2000; Sarkar et al., 2005; Sarkar and Acharya, 2006; Srivastava et al., 2006; Viraraghavan and Alfaro, 1998) has been reported by several other investigators before. However, the nature of fly ash is influenced by, amongst others, the origin of the coal and the burning conditions under which it was formed. It is therefore not unreasonable to expect South African coal fly ash to behave differently from those in other parts of the world. In fact, a previous study (Potgieter-Vermaak and Potgieter, 2006) confirmed that South African coal fly ash behaved very differently from other fly ashes reported in the literature with regard to the removal and successful uptake of heavy metal ions from contaminated water.

Apart from its heavy metal removal capacity, SACFA has been used previously to treat acid mine drainage (Potgieter-Vermaak et al., 2006), remove phosphates from wastewater (Agyei et al., 2002), as a source of metal oxides (Matjie et al., 2004) and for soil amelioration (Reynolds, 2005). However, no record could be found of its use to alleviate the occurrence of phenols in water. The current study thus investigates the suitability of SACFA to remove phenolic compounds from water. To this end, the kinetics of the adsorption process was investigated, due to the importance of its control of the process efficiency. Further- 
more, the applicability of the Freundlich and Langmuir adsorption isotherms was investigated, in order to understand the mechanism of the adsorption process and establish the adsorption capacity of the adsorbent fly ash. Lastly, the desorption of the phenolic compounds was considered to gauge the efficiency of the process. This study will add to the current knowledge of the characteristics and behaviour of South African fly ash, and its suitability as a potential adsorbent in various applications.

\section{Experimental procedure}

\section{Adsorbate material}

The composition of the synthetically prepared aqueous solutions used in this study was similar to that generated by the petrochemical, coal conversion and phenol producing industries. The stock solution was prepared by diluting the required quantities of phenol, 2- nitrophenol and 4-nitrophenol of AnalR grade supplied by Merck Chemical Ltd., South Africa, in the same volume of distilled water to obtain adsorbate solutions of various initial concentrations $\left(\mathrm{C}_{\mathrm{o}}\right)$ in the range of $10 \mathrm{mg} / \ell$ to $30 \mathrm{mg} / \ell$. The $\mathrm{pH}$ value for the aqueous solution of phenol, 2- nitrophenol and 4-nitrophenol $(10 \mathrm{mg} / \ell$ to $30 \mathrm{mg} / \ell)$ was adjusted with either dilute $\mathrm{HCl}$ or $\mathrm{NaOH}$ solutions to a constant value. All the $\mathrm{pH}$ measurements were done with a $\mathrm{pH}$ meter (827 $\mathrm{pH} \mathrm{Lab}$, Metrohm). Each flask was capped and inverted 3 times to mix the contents thoroughly and then allowed to stabilise for 10 to $15 \mathrm{~min}$ in the Pyrex conical flask until isotherm experiments for batch studies were performed.

\section{Adsorbent material}

Fly ash is the fine powdery residue obtained by separating the solids from the flue gases during the combustion of coal. The fly ash utilised in this investigation was an unclassified grade obtained from Lethabo Power Station in South Africa and collected using an electrostatic precipitator. The physico-chemical characteristics of the material were determined using standard procedures, and are summarised in Table 1.

\begin{tabular}{|l|c|}
\hline \multicolumn{2}{|c|}{ TABLE 1 } \\
Properties of SACFA used in this investigation \\
\hline Parameter & SACFA \\
\hline Physical form & Powdered \\
\hline Specific surface area $\left(\mathrm{S}_{\mathrm{BET}}\right)\left(\mathrm{m}^{2} / \mathrm{g}\right)$ & 1.279 \\
\hline Pore volume $\left(\mathrm{cm}^{3} / \mathrm{g}\right)$ & 0.001437 \\
\hline Particle size $(90 \%$ level $)(\mu \mathrm{m})$ & 99.91 \\
\hline Chemical composition $(\% \mathrm{~m} / \mathrm{m})$ & \\
\hline $\mathrm{SiO}_{2}$ & 45.24 \\
\hline $\mathrm{Al}_{2} \mathrm{O}_{3}$ & 34.26 \\
\hline $\mathrm{CaO}$ & 4.01 \\
\hline $\mathrm{Fe} \mathrm{O}_{3}$ & 2.87 \\
\hline $\mathrm{MgO}$ & 1.23 \\
\hline $\mathrm{TiO}$ & 1.32 \\
\hline $\mathrm{K}_{2} \mathrm{O}$ & 0.65 \\
\hline $\mathrm{P} \mathrm{O}_{5}$ & 0.54 \\
\hline $\mathrm{Na} \mathrm{O}_{2} \mathrm{O}$ & 0.40 \\
\hline $\mathrm{S}$ & 0.304 \\
\hline $\mathrm{Ba}$ & 0.113 \\
\hline $\mathrm{Sr}$ & 0.071 \\
\hline $\mathrm{Loss}$ on ignition & 1.35 \\
\hline
\end{tabular}

\section{Instrumental methods}

The particle sizes of the samples were measured using a laser based particle size analyser, namely a Mastersizer (2000) of Malvern Instruments Ltd. The surface areas of samples were determined by $\mathrm{N}_{2}$ adsorption at $-196{ }^{\circ} \mathrm{C}$ using a TriStat 3000 analyser (Micromeritics Instrument Corp). All samples were degassed at $200^{\circ} \mathrm{C}$ for $4 \mathrm{~h}$, prior to adsorption experiments.

Major element concentrations within the fly ash were determined by X-ray Fluorescence Spectroscopy, using a Magi "X Pro XRF spectrometer from PANalytical. The sample was placed in an aluminium cup and hydraulically pressed into pellets under very high pressure of $20 \mathrm{t}$ for $60 \mathrm{~s}$. This was done to ensure sample integrity under the vacuum and a consistent surface to receive the X-rays. Quantitative analysis was carried out with the Magi "X Pro XRF spectrometer at $40 \mathrm{kV}$ and $40 \mathrm{~mA}$, using $\mathrm{IQ}^{+}$'Standardless' analysis.

The phases and qualitative analyses of the minerals within the fly ash were carried out using a X "Pert PRO Diffractometer by PANanalytical, operated at $40 \mathrm{kV}$ and $40 \mathrm{~mA}$ for $1 \mathrm{~h}$ over the range of $2 \theta$ from $0^{\circ}$ to $80^{\circ}$. A Scanning Electron Microscopy (SEM) (model Jeol JSM840) was used to identify the minerals' morphology present in the fly ash.

The concentration changes of the individual compounds in the solutions were determined by means of UV-VIS spectrophotometry (SQ-4802 Double Beam). The maximum absorbances for each solute from the highest standard solution prepared were found using scanning spectrophotometry at the respective wavelength maxima $\lambda_{\max }$. The $\lambda_{\max }$ used were $269 \mathrm{~nm}, 277.5 \mathrm{~nm}$ and $320.5 \mathrm{~nm}$ for phenol, 2-nitrophenol and 4-nitrophenol respectively. The calibration plot of absorbance vs. concentration for all the standards showed a linear working range up to $30 \mathrm{mg} / \ell$ with correlation coefficient $\geq 0.99$. The supernatant solutions obtained after adsorption were also analysed using the same wavelengths.

\section{Adsorption kinetics}

Kinetic tests using a mixture of phenol, 2-nitrophenol and 4nitrophenol were performed in a batch fashion. The initial solutes mix was analysed to determine the initial concentration of the solutes before mixing with the fly ash. For each adsorption data point, a $30 \mathrm{~m} \ell$ aliquot of the adsorbate solution having an initial phenol, 2-nitrophenol and 4-nitrophenol concentration of $20 \mathrm{mg} / \ell$, constant fly ash loading of $20 \mathrm{~g}$ at temperature of $307 \mathrm{~K}$ were introduced into a series of $250 \mathrm{~m} \ell$ Pyrex conical flasks for different contact times and at a $\mathrm{pH}$ of about 3.12. The conical flasks were placed and shaken in a Labcon platform shaking incubator (Model FSIM-SPO16) where the last sample was collected after $360 \mathrm{~min}$ of contact time and at a constant stirring speed of $300 \mathrm{rpm}$. The samples were covered throughout the experiment and the supernatant solution filtered through Whatman micro-fibre filters of $0.45 \mu \mathrm{m}$ to determine the concentration of each solute left after the different time intervals of agitation. Data obtained from these tests were used in determining the rate constant for adsorption using the Lagergren model. The equilibrium adsorption studies at $307 \mathrm{~K}$ were conducted by contacting initial phenol, 2-nitrophenol and 4-nitrophenol concentrations of $20 \mathrm{mg} / \ell$ with varying quantities of fly ash (5 to 35) $\mathrm{g}$ in a series of $250 \mathrm{~m} \ell$ Pyrex conical flasks at a $\mathrm{pH}$ of $3.12 \pm 0.10$. The flasks were shaken in a Labcon platform shaking incubator (Model FSIM-SPO16) to attain equilibrium after about $22 \mathrm{~h}$ of contact time and at a constant stirring speed of $300 \mathrm{r} / \mathrm{min}$. This follows a similar approach by Gupta et al. (1998) who used an 
equilibrium adsorption time of $24 \mathrm{~h}$ in their investigation of phenol and 4-nitrophenol adsorption onto bagasse fly ash.

The second phase of the study dealt with the determination of the desorbabilities or reversibility of phenolic compounds adsorbed onto the fly ash. The kinetic tests were carried out in $250 \mathrm{~m} \ell$ Pyrex conical flasks by contacting a previously loaded set of fly ash/adsorbates with $30 \mathrm{~m} \ell$ of water for different time intervals at a temperature of $307 \mathrm{~K}$ and shaking it at $300 \mathrm{r} / \mathrm{min}$ to complete desorption equilibrium. After equilibrium the concentrations left were analysed as before.

Data obtained from the adsorption isotherm tests were used to determine the adsorption capacity of the fly ash. The equilibrium adsorption uptake and percentage removal of phenol from the aqueous solution $q_{e}(\mathrm{mg} / \mathrm{g})$ was determined using the following relationship:

Amount adsorbed $q_{e}=\frac{\left(C_{o}-C_{e}\right) V}{w}$

(mg of adsorbate / $\mathrm{g}$ of adsorbent)

$$
\text { and, } \% \text { removal } q_{e}=\frac{100\left(C_{o}-C_{e}\right)}{C_{o}}
$$

where:

$C_{0}$ is the initial sorbate concentration $(\mathrm{mg} / \ell)$

$C_{e}$ the equilibrium sorbate concentration $(\mathrm{mg} / \ell)$

$\mathrm{V}$ is the volume of solution $(\ell)$

$w$ is the mass of the adsorbent $(\mathrm{g})$

A series of desorption tests were used to determined the concentration of the desorbed phenol in the supernatant. Each desorption test was continued until a constant value of the desorbed phenol compound was reached in the supernatant. Desorption efficiencies for each of the adsorbates was calculated after each consecutive desorption step, using the following equation:

$$
q_{i}=\frac{X_{a}-\Sigma\left(X_{d}\right)_{i}}{W}
$$

where:

$X_{a}$ was the initial adsorbate loading on the fly ash (mg)

$X_{d e}^{a}$ is the mass of adsorbate desorbed after each $\mathrm{i}^{\text {th }}$ desorption step (mg)

$W$ is the weight of fly ash used in each desorption test $(\mathrm{g}) \backslash$

The total desorption of each phenol derivative was calculated using the formula:

$$
D E(\%)=\frac{C_{d e} V_{d e}}{W_{a} q_{e}} X 100
$$

where:

$C_{d e}$ is the desorbed adsorbate concentration $(\mathrm{mg} / \ell)$

$V_{d e}$ the volume of the desorption solution $(\ell)$

$W_{a}$ the mass of pre-adsorbed adsorbent $(\mathrm{g})$

$q_{e}$ is the amount of adsorbate pre-adsorbed on adsorbent $(\mathrm{mg} / \mathrm{g})$

\section{Results and discussion}

\section{Characterisation of adsorbents}

The $\mathrm{N}_{2}$ adsorption gave the specific surface area $\left(\mathrm{S}_{\mathrm{BET}}\right)$ and pore volume for the fly ash used in this analysis as $1.279 \mathrm{~m}^{2} / \mathrm{g}$ and $0.001437 \mathrm{~cm}^{3} / \mathrm{g}$, respectively. These results are comparable with those reported by Viraraghavan and Alfaro (1998) where the specific surface area (SSA) of the fly ash they used in adsorbing

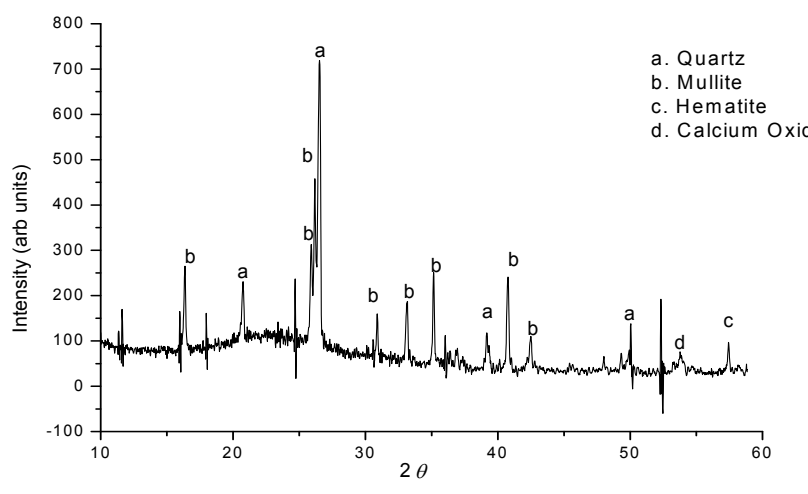

Figure 1

$X$-ray diffraction pattern of Lethabo FA

phenol from wastewater was within the range of 1.5 to $1.7 \mathrm{~m}^{2} / \mathrm{g}$, and which had an adsorption capacity for phenol in the range of 0.015 to $0.100 \mathrm{mg}$ of phenol per gram of adsorbent. However, the SSA was in contrast with the result reported by Kao et al. (2000), who found that the SSA of fly ash usually ranges from 5 to $42 \mathrm{~m}^{2} / \mathrm{g}$. The X-ray fluorescence (XRF) analysis of the fly ash used in this investigation is given in Table 1. The particle size of the fly ash used for the current experiments is also shown in Table 1.

\section{XRD analysis}

The identification of the mineralogical constituents and phase proportions of fly ash was conducted by X-Ray diffractometer (XRD) on a model Philips PW 1830 X-ray diffractometer with a $\mathrm{Cu}$-anode and X "Pert PRO Diffractometer by PANanalytical, and is given in Fig. 1.

It can be observed from Fig. 1 that the fly ash consists mostly of mullite, quartz, a small amount of hematite and calcium oxide with large characteristic peaks of quartz $\left(\mathrm{SiO}_{2}\right)$. This composition is similar to that reported for a fly ash investigated by Sarkar et al. (2006). The intensity of quartz is very strong with mullite forming a chemically stable and dense glassy surface layer. The low calcium oxide intensity is characteristic of low-Ca Class-F fly ash and similar to that reported by Giere et al. (2003).

\section{SEM analysis}

The investigation reveals that most of the particles present in the fly ash are spherical in shape with a relatively smooth surface. Figure 2 shows sub-angular and spherical particles with relatively smooth grains consisting of quartz, while Fig. 3 shows clusters of iron (Fe-oxide) particles formed due to partial decomposition of pyrite and with dark quartz inclusions. Similar results were obtained from the investigation conducted by Matjie et al. (2004) on Sasol ashes.

\section{Adsorption time}

Figure 4 represents the results for the effect of contact time on the removal of phenol, 2-nitrophenol and 4-nitrophenol from aqueous solution at an initial concentration of $20 \mathrm{mg} / \ell$.

It can be seen that the amount of all the adsorbates adsorbed onto fly ash increases with time and about $75.4 \%$, $73.2 \%$ and $84.8 \%$ of phenol, 2-nitrophenol and 4-nitrophenol had been removed within the first 15 min of agitation, respectively, after which the process approaches equilibrium. The time profile for the adsorbates is a single, smooth, and 

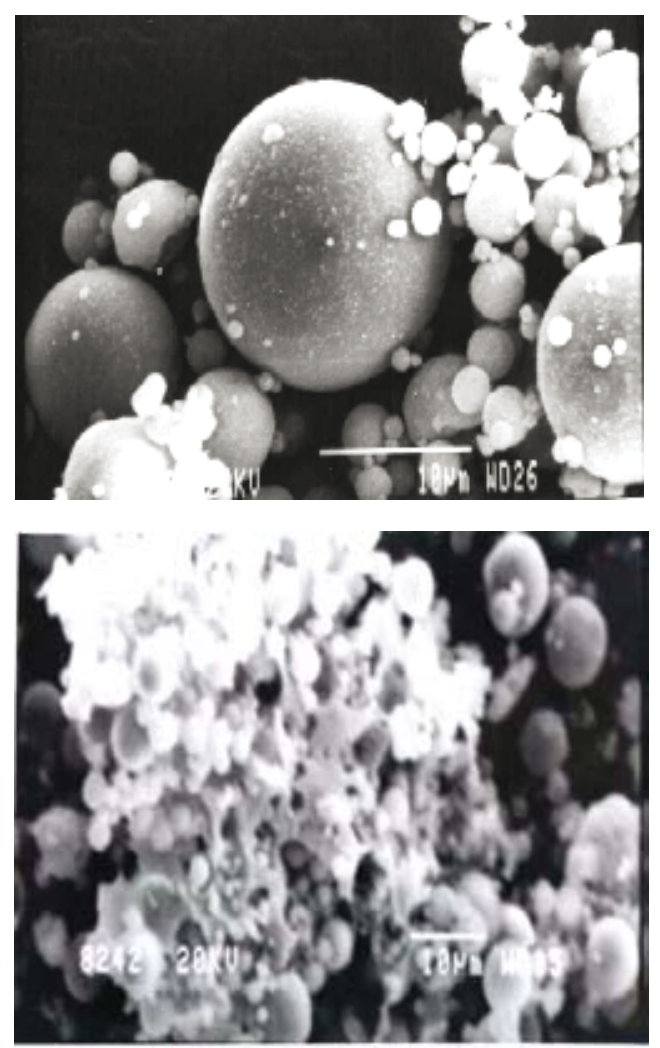

Figure 2 and 3

SEM micrographs of the fly ash used

continuous curve leading to saturation, which suggests possible monolayer coverage of the adsorbates on the surface of the fly ash. The adsorption capacity $\left(Q_{t}\right)$, as illustrated in Fig. 5, generally increases with increase in contact time, and the adsorption equilibrium reached values as high as $2.60 \times 10^{-2} \mathrm{mg} / \mathrm{g}, 2.33 \times 10^{-2} \mathrm{mg} / \mathrm{g}$, and $2.23 \times 10^{-2} \mathrm{mg} / \mathrm{g}$ for 4-nitrophenol, phenol and 2-nitrophenol respectively after $360 \mathrm{~min}$ of agitation. Further increases in adsorption capacity after the first $360 \mathrm{~min}$ of contact time, will be dependent on the creation of some fresh internal surfaces (Giles et al., 1974). 4-nitrophenol was found to adsorb more than phenol, probably due to its lower solubility in aqueous solution and because the more non-polar an organic compound, the less its affinity for solvent and the higher its adsorption affinity by the adsorbent (Cooney, 1999). The adsorption capacity for phenol was found to be slightly higher than that of 2-nitrophenol and this shows that solubility is not the all-important parameter in this phenomenon. The difference in adsorption behaviour of phenol, 2-nitrophenol and 4-nitrophenol might also be due to the different affinities of the three phenolic species for the reactive functional groups on the fly ash. Apart from hydrophobic interaction, Van der Waals interactions and hydrogen bonding interaction can also play a role in this regard (Senel et al., 2006). Denizli et al. (2002) reported that the adsorption capacity for phenol and 4-nitrophenol on micro-beads were found to be greater than that of 2-nitrophenol.

\section{Dynamic adsorption}

The data from the kinetic adsorption of phenol, 2-nitrophenol and 4-nitrophenol with fly ash were modelled using the pseudo first-order Lagergren equation. The Lagergren equation is one of

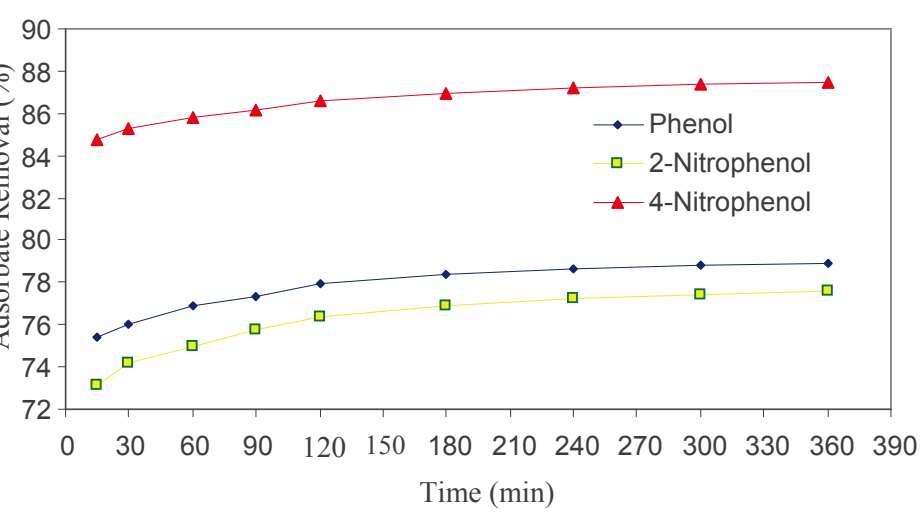

Figure 4

Effect of contact time on the\% amount of phenol, 2-nitrophenol and 4-nitrohenol removed from aqueous solution with fly ash (operating conditions: $\mathrm{C}_{0} .20 \mathrm{mg} / \mathrm{l}, 300 \mathrm{r} / \mathrm{min}$, fly ash: $20 \mathrm{~g}, \mathrm{pH}: 3.12$ and volume: $30 \mathrm{ml}$ )

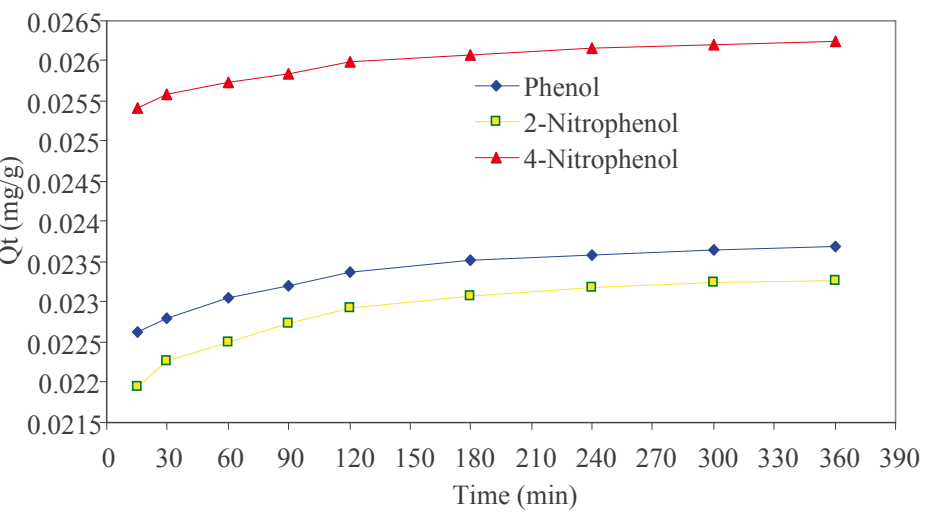

Figure 5

ffect of contact time on the amount of phenol, 2-nitrophenol and 4-nitrohenol removed from aqueous solution with fly ash (operating conditions:

$\mathrm{C}_{\mathrm{o}} 20 \mathrm{mg} / \mathrm{\ell}, 300 \mathrm{r} / \mathrm{min}$, fly ash: $20 \mathrm{~g}, \mathrm{pH}: 3.12$ and volume: $30 \mathrm{ml}$ )

the most widely used for the adsorption of solute from a liquid solution. It can be written as:

$$
\log \left(q_{e}-q\right)=\log q_{e}-\frac{k_{a d}}{2.303} t
$$

where:

$k_{a d}$ is the rate constant of pseudo-first-order adsorption $\left(\mathrm{min}^{-1}\right)$

$q_{e}$ and $q$ denote the amounts of adsorbed phenol (or derivatives) at equilibrium and at time $t$ (min)

A plot of $\log \left(q_{e}-q\right)$ vs. time should give a straight line to confirm the applicability of the kinetic model, and a derivation of the constant. Figure 6 shows a plot of $\log \left(q_{e}-q_{t}\right)$ vs. $t$ for the phenol, 2-nitrophenol and 4-nitrophenol adsorption at a concentration of $20 \mathrm{mg} / \ell$.

The data depicted in Fig. 6 show that a first order reaction rate expression was obeyed to a reasonable degree, and the value of $K_{a d}$ for the adsorption of the various adsorbates onto the fly ash was found to be $1.15 \times 10^{-3} / \mathrm{h}$ for phenol, $1.0 \times 10^{-3} / \mathrm{h}$ for 2-nitrophenol and $6.32 \times 10^{-3} / \mathrm{h}$ for 4-nitrophenol.

\section{Adsorption mechanisms}

The adsorption equilibrium was described using both Freundlich and Langmuir isotherms model. The rearranged Langmuir 


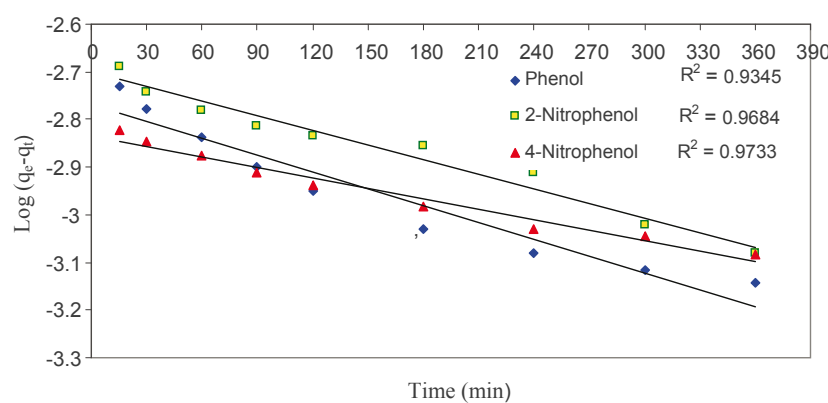

Figure 6

Linear plot of $\log \left(q_{e}-q_{t}\right)$ vs. $t$ for the kinetic adsorption of phenol, 2-nitrophenol and 4-nitrophenol studied at concentration of $20 \mathrm{mg} / \mathrm{l}$

isotherm can be described as:

$$
\frac{1}{Q}=\frac{1}{Q_{m}}+\left(\frac{1}{b Q_{m}}\right)\left(\frac{1}{C_{e}}\right)
$$

where:

$b$ is an adsorption equilibrium constant related to the binding energy

The Langmuir adsorption isotherm is based on the concept that solid surfaces have finite adsorption sites. When all the adsorption sites are filled, the surface will no longer be able to adsorb solute from the solution. The maximum amount of solute $\left(\mathrm{Q}_{m}\right)$ adsorbed in a particular system can be estimated from the isotherm parameters. The plot of $1 / \mathrm{Q}$ vs. ${ }^{1 /} \mathrm{C}$ should yield a straight line. The slope is $1 / \mathrm{Q}$ and the intercept is $1 / \mathrm{bQ}$.

The Freundlich adsorption isotherm can be written in the form:

$$
\log Q=\log K_{f}+1 / \mathrm{n} \log C_{e}
$$

The Freundlich isotherm predicts that the adsorbate concentration on the surface of an adsorbent will increase when there is an increase in the initial adsorbate concentration in the aqueous solution. The experimental data obtained are plotted as $\log Q_{e}$ versus $\log C_{e}$, to obtain the constants $K_{f}$ and $1 / \mathrm{n}$. The constant $K_{f}$ is a comparative measure of the adsorption capacity of the adsorbent, while $n$ is an empirical constant. The magnitude of $n$ gives an indication of the favourability of adsorbent/adsorbate system. Values of $n>1$ signify that the solute has a low affinity for the adsorbent at low concentrations. Likewise, a value of $n$ $<1$ is an indication of favourable adsorption and a high affinity between the solute and the solid phase.

The Freundlich $\left(K_{f}\right.$ and $\left.1 / \mathrm{n}\right)$ and Langmuir constants $(b$ and $Q_{m}$ ) determined from the adsorption isotherms for phenol, 2-nitrophenol and 4-nitrophenol depicted in Figs. 7 and 8 are summarised in Table 2.

The correlation coefficient values determined for each of the adsorption isotherms indicates that the Freundlich model effec-

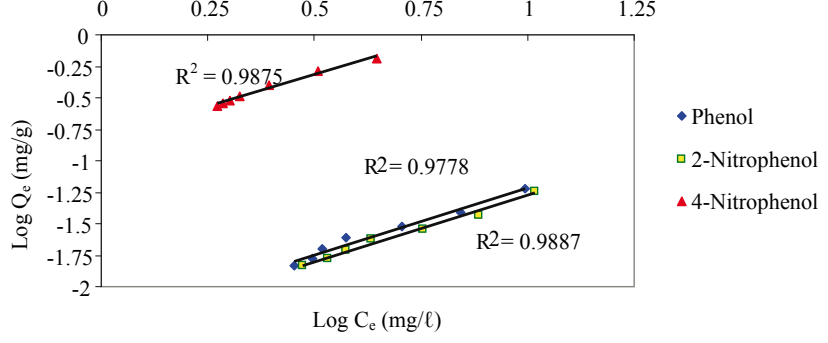

Figure 7

The linearised Freundlich adsorption isotherm for phenol, 2-nitrophenol and 4-nitrophenol mixtures onto fly ash

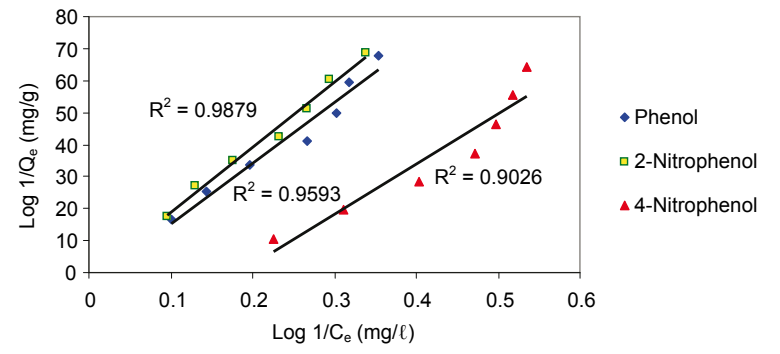

Figure 8

The linearised Langmuir adsorption isotherm for phenol, 2-nitrophenol and 4-nitrophenol mixtures onto fly ash

tively fits the experimental data better than the Langmuir model. The value for $n$ was found to be greater than 1 for the fly ash, which suggested unfavourable uptake of the adsorbates by the fly ash. The adsorption capacity for phenol, 2-nitrophenol and 4-nitrophenol at the maximum residual concentration was calculated using the Freundlich constants $\left(K_{f}\right.$ and $\left.1 / \mathrm{n}\right)$ at an initial concentration of $20 \mathrm{mg} / \ell$ for all the adsorbates and the values obtained were $5.79 \times 10^{-2} \mathrm{mg} / \mathrm{g}, 5.47 \times 10^{-2} \mathrm{mg} / \mathrm{g}$ and $6.33 \times 10^{-2}$ $\mathrm{mg} / \mathrm{g}$ for phenol, 2-nitrophenol and 4-nitrophenol, respectively. The adsorption capacity for the adsorbates when applying the Langmuir constant under the same conditions and at the maximum residual concentration were found to be $4.37 \times 10^{-2} \mathrm{mg} / \mathrm{g}$, $4.76 \times 10^{-2} \mathrm{mg} / \mathrm{g}$ and $5.62 \times 10^{-2} \mathrm{mg} / \mathrm{g}$. The $K_{f}$ value determined for fly ash on the adsorption of phenol from the solution was found to be higher than that of 2-nitrophenol and lower when compared to 4-nitrophenol within the same concentration ranges studied. The higher adsorption affinity of fly ash for 4-nitrophenol was expected due to its lower solubility in water than phenol. 4-nitrophenol is moderately soluble in cold water and denser than water $(1.52 \mathrm{~g} / 100 \mathrm{~m} \ell)$, while the solubility of 2-nitrophenol in water is $(0.26 \mathrm{~g} / 100 \mathrm{~m} \ell)$ and phenol is $(8.3 \mathrm{~g} / 100 \mathrm{~m} \ell)$ under the same condition $(273 \mathrm{~K})$. Both 2-nitrophenol and 4-nitrophenol have the same molecular weight, and therefore it seems that solubility is not the overriding factor for this test when considering the higher amount of 4-nitrophenol adsorbed onto fly ash compared to 2-nitrophenol. The result is in agreement with the findings

\begin{tabular}{|c|c|c|c|c|c|c|}
\hline \multicolumn{7}{|c|}{$\begin{array}{c}\text { TABLE } 2 \\
\text { Freundlich and Langmuir adsorption isotherm parameters }\end{array}$} \\
\hline \multirow[t]{2}{*}{ Adsorbates } & \multicolumn{3}{|c|}{ Freundlich constants } & \multicolumn{3}{|c|}{ Langmuir constants } \\
\hline & $K_{f}(\mathrm{mg} / \mathrm{g})$ & $n(\ell / m g)$ & $\mathbf{R}^{2}$ & $Q_{m}(\mathrm{mg} / \mathrm{g})$ & $b(\ell / m g)$ & $\mathbf{R}^{2}$ \\
\hline Phenol & 0.0579 & 1.058 & 0.9778 & 0.270 & 0.0195 & 0.9593 \\
\hline 2-Nitrophenol & 0.0540 & 1.037 & 0.9887 & 0.564 & 0.008 & 0.9879 \\
\hline 4-Nitrophenol & 0.0633 & 1.001 & 0.9875 & 0.145 & 0.0845 & 0.9256 \\
\hline
\end{tabular}
of Denizli et al. (2002) where more 4-nitrophenol was found to 
adsorb onto micro-beads than 2-nitrophenol.

The adsorption capacity of the adsorbent used in this investigation was found to be lower than that of many other fly ashes and activated carbons. The main reason could be the high surface area of activated carbon, which is usually in the range of 500 to $1500 \mathrm{~m}^{2} / \mathrm{g}$ (Yin et al., 2007). In addition, the surface area of the fly ash and activated carbon reported by Srivastava et al. (2006) for the uptake of phenol were $168.39 \mathrm{~m}^{2} / \mathrm{g}$ and 336.60 $\mathrm{m}^{2} / \mathrm{g}$ respectively.

The adsorption results from this study were compared to those previously found by other authors in Table 3 . The value of $K_{f}$ was found to be significantly higher for the phenol-SACFA system in comparison to phenol-rice husk and phenol-coke breeze described by Mahvi et al. (2004). Also, the constant $K_{f}$ value obtained for this system was in contrast to the result reported by Viraraghavan and Alfaro (1998) for phenol-bentonite and phenol-peat systems. The adsorption capacity for phenol varies widely among the different adsorbents, thus again underlining the necessity and importance to characterise and investigate each adsorbent intended for pilot or plant use.

The nature and composition of fly ashes are influenced by the coal origin and the existing burning conditions under which it were formed. Therefore, it is to be expected that these ashes should have different adsorption capacities for the uptake of adsorbates. The adsorption capacity for the fly ash used by Sarkar et al. (2005) was found to be much higher than the fly ash used in this investigation. Furthermore, the result was also in contrast with the findings of Ahmaruzzaman and Sharma (2005) and this is due to the fact that the coal ash used in their investigation had a higher specific surface area within the range of 96.44 and $312.56 \mathrm{~m}^{2} / \mathrm{g}$. The South African fly ash used in this work had an SSA of $1.279 \mathrm{~m}^{2} / \mathrm{g}$ and pore volume of $0.001437 \mathrm{~cm}^{3} / \mathrm{g}$, which seems to perform almost equally compare to the rubber activated carbon with SSA of $596 \mathrm{~m}^{2} / \mathrm{g}$ used for adsorbing phenol by Rengaraj et al. (2002b).

\section{Desorption studies}

The adsorption-desorption efficiencies shown in Fig. 9 and summarised in Table 4 reveal that the desorption of 4-nitrophenol from the fly ash was more difficult than 2-nitrophenol, and its adsorption was more irreversible than that of phenol and 2-nitrophenol on the adsorbent. The irreversibility of adsorption in this case could possibly be due to high-energy bonding to specific functional groups on the surface of the fly ash that might have resulted in a degree of chemisorption. This work shows that 4-nitrophenol was adsorbed with a higher adsorption efficiency of $92.6 \%$ compared to both phenol $90.2 \%$ and 2-nitrophenol $88.9 \%$. The desorption efficiency for 2-nitrophenol was $18.8 \%$ when using $30 \mathrm{~m} \ell$ of distilled water to desorbed phenol from fly ash. Hence, from the initial concentration of $20 \mathrm{mg} / \ell$ of the adsorbates, $20 \mathrm{~g}$ of fly ash adsorbed $16.45 \mathrm{mg} / \ell$ of phenol, 16.01 $\mathrm{mg} / \ell$ of 2-nitrophenol and $18.13 \mathrm{mg} / \ell$ of 4-nitrophenol from the solution. The concentrations for the 3 adsorbates released after

\begin{tabular}{|c|c|c|c|c|c|c|c|}
\hline \multicolumn{8}{|c|}{$\begin{array}{c}\text { TABLE } 3 \\
\text { A comparison of Freundlich and Langmuir constants for phenol adsorption reported in the literature }\end{array}$} \\
\hline \multirow[t]{2}{*}{ Adsorbent } & \multirow[t]{2}{*}{ Adsorbate } & \multicolumn{2}{|c|}{ Langmuir } & \multicolumn{2}{|c|}{ Freundlich } & \multirow{2}{*}{\begin{tabular}{|c|} 
Adsorption \\
capacity $(\mathrm{mg} / \mathrm{g})$ \\
$\left(\begin{array}{c}7 \mathrm{~s} \text { almost } 360 \\
\text { minutes })\end{array}\right.$ \\
\end{tabular}} & \multirow{2}{*}{ Reference } \\
\hline & & $Q_{m}(\mathrm{mg} / \mathrm{g})$ & $b(\ell / m g)$ & $K_{f}(\mathrm{mg} / \mathrm{g})$ & $n(\ell / m g)$ & & \\
\hline Coke breeze & Phenol & 0.172 & 0.00150 & 0.917 & 0.350 & 0.180 & $\begin{array}{l}\text { Ahmaruzzaman and } \\
\text { Sharma (2005) }\end{array}$ \\
\hline Activated C & Phenol & & & & & 0.301 & Ravi et al. (1999) \\
\hline Petroleum coke & Phenol & 6.010 & 0.00267 & 0.259 & 2.41 & 6.00 & $\begin{array}{l}\text { Ahmaruzzaman and } \\
\text { Sharma (2005) }\end{array}$ \\
\hline Rice husk & Phenol & 0.0022 & 30.7 & 0.00092 & 5.13 & & Mahvi et al. (2004) \\
\hline Rice husk ash & Phenol & 0.886 & 5.15 & 0.00092 & 1.75 & 0.886 & Mahvi et al. (2004) \\
\hline $\begin{array}{l}\text { Dried activated } \\
\text { sludge }\end{array}$ & Phenol & & & & & 0.149 & Aksu and Yener (1999) \\
\hline $\begin{array}{l}\text { Phanerochaete } \\
\text { Biomass }\end{array}$ & $\begin{array}{l}\text { 2, 4-dichloro- } \\
\text { phenol }\end{array}$ & & & 0.187 & 1.21 & & Wu J and Yu HQ (2006) \\
\hline Peat & Phenol & & & 0.201 & 0.21 & & Srivastava et al. (2006) \\
\hline Peat & Phenol & & & $4.6 \times 10^{-10}$ & & & $\begin{array}{l}\text { Viraraghavan and } \\
\text { Alfaro(1998) }\end{array}$ \\
\hline Bentonite & Phenol & & & 0.0362 & 0.64 & & Srivastava et al. (2006) \\
\hline Bentonite & Phenol & & & $5.1 \times 10^{-8}$ & & & $\begin{array}{l}\text { Viraraghavan and } \\
\text { Alfaro(1998) }\end{array}$ \\
\hline $\begin{array}{l}\text { Clay-Zeolite } \\
\text { (Al-Si based) }\end{array}$ & Phenol & & & & & 0.100 & Shu et al. (1997) \\
\hline Coal fly ash & $\begin{array}{l}\text { 2, 4-dimethyl } \\
\text { phenol }\end{array}$ & 2.730 & 0.00917 & 1.88 & 1.77 & 0.780 & Batabyal et al. (1995) \\
\hline Fly ash & Phenol & 13.16 & 0.0129 & 0.8787 & 2.25 & & Sarkar et al. (2006) \\
\hline Fly ash & Chlorophenol & & & 3.76 & 208.33 & & Kao et al.(2000) \\
\hline Bagasse FA & Phenol & & & 0.003 & 4.66 & & Mukherjee et al. (2007) \\
\hline Bagasse FA & Phenol & & & & & 0.060 & Gupta et al. (1998) \\
\hline SACFA & $\begin{array}{l}\text { Phenol } \\
\text { 2-nitrophenol } \\
\text { 4-nitrophenol }\end{array}$ & $\begin{array}{l}0.284 \\
0.461 \\
0.110\end{array}$ & $\begin{array}{l}0.029 \\
0.015 \\
0.042\end{array}$ & $\begin{array}{l}0.0082 \\
0.0066 \\
0.1150\end{array}$ & $\begin{array}{l}1.083 \\
1.025 \\
1.267 \\
\end{array}$ & $\begin{array}{l}0.063 \\
0.060 \\
0.065\end{array}$ & Present work \\
\hline
\end{tabular}




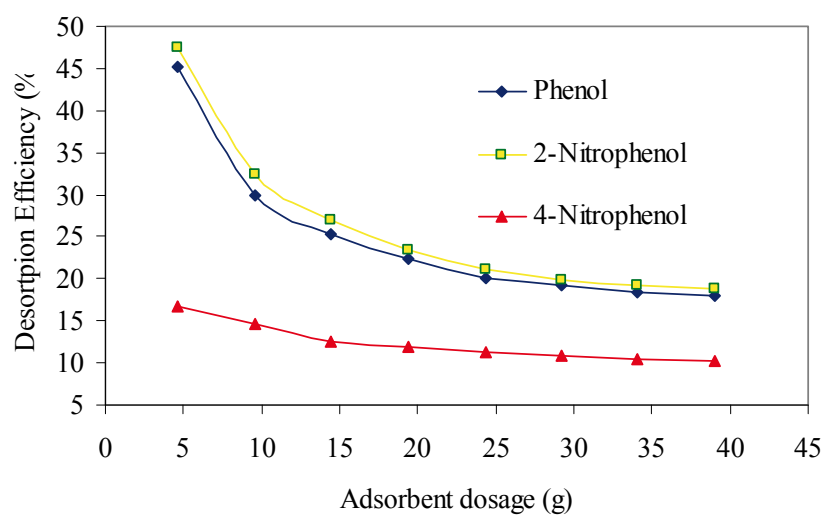

Figure 9

Influence of adsorbent dosage on the desorption of phenol, 2-nitrophenol and 4-nitrophenol from fly ash

replacing the supernatant solution with distilled water for the desorption test were $3.00 \mathrm{mg} / \ell$ for phenol, $3.04 \mathrm{mg} / \ell$ for 2-nitrophenol and $1.92 \mathrm{mg} / \ell$ for 4-nitrophenol.

\section{Conclusions}

The following conclusions can be drawn from this investigation:

- The adsorption process obeys first-order kinetics. The Freundlich isotherm fits and describes the adsorption mechanism better than the Langmuir one for all three phenol derivatives. The Freundlich constant (n) indicates that the affinity of the adsorbent for the adsorbates is not particularly favourable or strong.

- The values of the adsorption capacity, as well as the Freundlich and Langmuir isotherm constants, which were obtained in this work, are comparable to those of some other adsorption systems, but different. This once again emphasises the necessity to investigate and characterise each system individually before attempting any pilot plant or full-scale design for implementation. Desorption occurs to a much lesser extent than adsorption, thus implying that the fly ash investigated in this work could be employed to remove and retain a substantial amount of phenols from solution. This work proved that SACFA have all the necessary adsorption attributes and characteristics to warrant serious consideration for potential application in wastewater treatment applications.

\section{Acknowledgements}

The authors wish to thank Ash Resources (Pty) Ltd for supplying the fly ash used in this investigation. The University of the Witwatersrand is acknowledged for partial financial support and the use of their facilities.

\section{References}

ABBURI K (2003) Adsorption of phenol and $p$-chlorophenol from their single and bisolute aqueous solutions on Amberlite XAD-16 resin. J. Hazard. Mater. 105 143-156.

AGYEI NM, POTGIETER JH and STRYDOM CA (2002) The removal of phosphate ions from aqueous solution by fly ash, slag, ordinary cement and related blends. Cem. Concr. Res. 32 1889-1897.

AKGERMAN A and ZARDKOOHI M (1996) Adsorption of phenolic compounds on fly ash. J. Chem. Eng. Data. 41 185-187.

AKSU Z (2005) Application of biosorption for the removal of organic

\begin{tabular}{|l|c|c|}
\hline \multicolumn{3}{|c|}{$\begin{array}{c}\text { TABLE 4 } \\
\text { Adsorption and desorption efficiencies of phenol, } \\
\text { 2-nitrophenol and 4- nitrophenol at maximum } \\
\text { fly ash loading }\end{array}$} \\
\hline $\begin{array}{l}\text { Adsorbates } \\
\text { (mg/l) }\end{array}$ & $\begin{array}{c}\text { Desorption } \\
\text { efficiency (\%) }\end{array}$ & $\begin{array}{c}\text { Adsorption } \\
\text { efficiency (\%) }\end{array}$ \\
\hline Phenol & 17.9 & 90.2 \\
\hline 2-nitrophenol & 18.8 & 88.9 \\
\hline 4-nitrophenol & 10.2 & 92.6 \\
\hline
\end{tabular}

pollutants: A review. Process Biochem. 40 997-1026.

AKSU Z and YENER J (1998) Investigation of the biosorption of phenol and monochlorinated phenols on the dried activated sludge. Process Biochem. 33 649-655.

ALLEN SJ (1987) Equilibrium adsorption isotherms for peat. Fuel 66 1169-1175.

AHMARUZZAMAN M and SHARMA DK (2005) Adsorption of phenols from wastewater. J. Colloid Interface Sci. 287 14-24

ATUN G (1992) The adsorption of nitrophenols on a special adsorbent prepared from glass powder. Spectrosc. Lett.1992 25 (5) 741-756.

BATABYAL D, SAHU A and CHAUDHURI SK (1995) Kinetics and mechanism of removal of 2, 4-dimethylphenol from aqueous solutions with coal fly ash. Sep. Technol. 5 179-186.

BARHOUMI M, BEURROIES I, DENOYEL R, SAID H and HANNA $\mathrm{K}$ (2003) Co-adsorption of alkylphenols and nonionic surfactants onto kaolinite. Colloids Surf A. 219 25-33.

BAYAT B (2002) Comparative study of adsorption properties of Turkish fly ashes: I. The case of nickel(II), copper(II) and zinc(II). J. Hazard. Mater. B95 251-273.

BERTONCINI C, RAFFAELLI J, FASSINO L, ODETTI HS and BOTANI EJ (2003) Phenol adsorption on porous and non-porous carbons. Carbon 41 (6) 1101-1111.

BRANDT S, ZENG A and DECKWER DW (1997) Adsorption and desorption of pentachlorophenol on cells of Mycobacterium chlorophenolicum PCP-1. Biotechnol. Bioeng. 55 480-489.

BÜLBÜL G, AKSU Z and TURKISH J (1997) Investigation of wastewater treatment containing phenol using free and Ca-alginate gel immobilized $P$. putida in a batch stirred reactor. Turkish J. Eng. Environ. Sci. 21 175-183.

COONEY DO (1999) Adsorption Design for Wastewater Treatment. Lewis Publisher, Washington, DC, USA.

DENIZLI A, OKAN G and UCAR M (2002) Dye-affinity microbeads for removal of phenols and nitrophenols from aquatic systems. J. Appl. Polym. Sci. 83 2411-2418.

DENIZLI A, CIHANGER N, TANER A, TANER M and ALSANCAK G (2004) Removal of chlorophenols from synthetic solutions using Phanerochaete chrysosporium. Process Biochem. 39 2025-2030.

DENILZI A, CIHANGER N, TÜZMEN N and ALSANCAK G (2005) Removal of chlorophenols from aquatic systems using the dried and dead fungus Pleurotus sajor caju. Bioresour. Technol. 96 (1) 59-62.

ENVIRONMENTAL PROTECTION AGENCY (1984) Methods 604, Phenols in Federal Register. October 26, Part VIII, 40, CFR, 58, USA.

GANGOLIN, MARKEY DC and THODOS G (1975) Removal of Heavy Metals Ions from Aqueous Solutions with Fly Ash. In: Proc. $2^{\text {nd }}$ Nat. Conf. on Complete Water Reuse: Water's Interface with Energy, Air and Solids. Chicago, IL. AIChE 3 270-275.

GARCIA-ARAYA JF, BELTRAN FJ, ALVAREZ P and MASA FJ (2003) Activated carbon adsorption of some phenolic compounds present in agro industrial wastewater. Adsorption 9 (1) 107-115.

GIERE R, CARLETON LE and LUMPKIN RG (2003) Micro- and nanochemistry of fly ash from a coal-fired power plant. Am. Mineral. 88 1853-1865.

GILES H, SMITH D and HUITSON A (1974) A general treatment and classification of the solute adsorption isotherm (II). J. Colloid Interface Sci. 47 766-778.

GREMINGER DC, BURNS GP, LYNN S, HANSON DJ and KING CJ (1982) Solvent-extraction of phenols from water. Ind. Eng. Chem. 21 51-54. 
GUPTA VK, SHARMA S, YADAV IS and MOHAN D (1998) Utilization of bagasse fly ash generated in the sugar industry for the removal and recovery of phenol and p-nitrophenol from wastewater J. Chem. Technol. Biotechnol. 71 180-186.

HANNA K, BEURROIES I, DENOYERL R, DESPLANTIERGISCARD D, GALARNEU A and DI RENZO F (2002) Sorption of hydrophobic molecules by organic/inorganic mesostructures. J. Colloid Interface Sci. 252 276-283.

KAO PN, TZENG JH and HUANG TL (2000) Removal of chlorophenols from aqueous solution by fly ash. J. Hazard. Mater. 76 237-249.

KHALID M, JOLY G, RENAUD A and MAGNOUX P (2004) Removal of phenol from water by adsorption using zeolites. Ind. Eng. Chem. Res. 43 5275-5280.

KOH S and DIXON JB (2001) Preparation and application of organominerals as adsorbents of phenol, benzene and toluene. Appl. Clay Sci. 18 111-122.

LAGERGEN S and SUENSKA VETENSK KUNGL (1898). Handl. 24 1-39.

MATJIE RH, BUNT JR and VAN HEERDEN JHP (2004). Extraction of alumina from coal fly ash generated from a selected low rank bituminous South Africa coal. Miner. Eng. 18 299-310.

MAHVI AH, MALEKI A and ESLAMI A (2004) Potential of rice husk and rice husk ash for phenol removal in aqueous systems. Am. J. Appl. Sci. 1 (4) 321-326.

MUKHEREJEE S, KUMAR S, MISRA AK and FAN M (2007) Removal of phenols from a waste water environment by activated carbon, bagasse ash and wood charcoal. Chem. Eng. J. 129 133-142.

MUNAF E, ZEIN R, KURNIADI R and KURNIADI I (1997) The use of rice husk for removal of phenol from waste water as studied using 4-aminoantipyrine spectrophotometric method. Environ. Technol. 18 (3) $355-358$

NOURI S, HAGHSERESHT F and MAX LU GQ (2002) Comparison of adsorption capacity of p-Cresol and p-Nitrophenol by activated carbon in single and double solute. Adsorption 8 (3) 215-223.

POTGIETER JH and POTGIETER-VERMAAK SS (2006) A comparison of the adsorption of heavy metals from multicomponent solutions onto industrial clay and fly ash. Proc. Int. Conf. Coal Ash. 2-4 October 2006, Pretoria, South Africa.

POTGIETER-VERMAAK SS, POTGIETER JH, VAN GRIEKEN R and MONAMA PP (2006) Comparison of limestone, dolomite and fly ash as pre-treatment agents for acid mine drainage. Miner. Eng. 19 454-462.

RAVI PV, JASRA RV and BHAT RSG (1998) Adsorption of phenol, cresol isomers and benzyl alcohol from aqueous solution on activated carbon at 278, 298 and 323 K. J. Chem. Technol. Biotechnol. 71 173-179.
RENGARAJ S, MOON SH, SIVABALAN R, ARABINDOO B and MURUGESAN V (2002b) Removal of phenol from aqueous solution and resin manufacturing industry wastewater using an agricultural waste: rubber seed coat. J. Hazard. Mater. B 89 185-196.

REYNOLDS K (2005) The utilization of ash wall for the control and treatment of acid mine drainage. World of Coal Ash Conference. Lexington, Kentucky, April11-25, 2005, USA.

SARKAR M, ACHARYA KP and BHATTACHARYA B (2005) Removal characteristics of some priority organic pollutants from water in a fixed bed fly ash column. J. Chem. Technol. Biotechnol. 80 1349-1355.

SARKAR M and ACHARYA KP (2006) Use of fly ash for the removal of phenol and its analogues from contaminated water. Waste Manage. 26 559-570.

SARKAR A, BASSU AK, UDAYBHANU G and RANO R (2006) A comprehensive characterization of fly ash from a thermal power plant in Eastern India. Fuel. 87 259-277.

SENEL S, KARA A, ALSANCAK G and DENIZLI A (2006) Removal of phenols and chlorophenol from water with reuseable dye-affinity hollow fibres. J. Hazard. Mater. 138 (2) 317-324.

SHU HT, LI D, SCALA AA and YI HM (1997) Adsorption of small organic pollutants from aqueous streams by aluminosilicate-based microporous materials. Sep. Purif. Technol. 11 27-36.

SISMANOGLU T and PURA S, (2001) Adsorption of aqueous nitrophenols on clinoptilolite. Colloids Surf. A. 180 1-2.

SLEIN MW and SANSONE EB (1980) Degradation of Chemical Carcinogens. Van Nostrand Reinhold, New York, USA.

SRIVASTAVA VC, SWAMY MM, MALL ID, PRASAD B and MISHRA IM (2006) Adsorptive removal of phenol by bagasse fly ash and activated carbon: Equilibrium, kinetics and thermodynamics. Colloids Surf. A. 272 89-104.

VIRARAGHAVAN T and ALFARO F (1998) Adsorption of phenol from wastewater by peat, fly ash and bentonite. J. Hazard. Mater. 57 59-70.

WAGNER K and SCHULTZ S (2001) Adsorption of phenol, chlorophenols, and dihydroxybenzens onto unfunctionalized polymeric resins at temperatures from $294.15 \mathrm{~K}$ to $318.15 \mathrm{~K}$. J. Chem. Eng. Data. 46 322-330.

WU J and YU HQ (2006) Biosorption of 2, 4-dichlorphenol from aqueous solution by Phanerochaete chrysosporium biomass: Isotherms, Kinetics and thermodynamics. J. Hazard. Mater. B 137 498-508.

YIN YC, AROUA MK and WAN DAUD WM (2007) Review of modifications of activated carbon for enhancing contaminant uptakes from aqueous solutions. Sep. Purif. Technol. 52 403-415. 